\title{
World War 1 Antiseptic Working Miraculously in Complicated Wounds
}

\author{
Vipul Gurjar', Viraj Narola ${ }^{2}$, Bhavin Shah $^{3}$ \\ ${ }^{1}$ Professor, ${ }^{2}$ Resident, ${ }^{3}$ Associate Professor, Smt. B.K. Shah Medical Institute and Research Centre, Sumandeep \\ Vidyapeeth Deemed to be university (An Institution), Pipariya Vadodara
}

\begin{abstract}
Introduction: Diabetic foot and complicated ulcers are relatively common occurrence in daily surgical to patient department for managing them various dressing materials and solutions are available. One of such is acriflavine emulsion.
\end{abstract}

Case Presentation: Both patients were diabetic having large ulcers over leg $2^{\text {nd }}$ was Hepatitis B positive also having large leg ulcer due to insect bite. In both Acriflavine emulsion was used as dressing material. STSG was performed in both and graft were accepted with uneventful post op course

Discussion: Acriflavine made from acridine has a local antiseptic property with Antimicrobial and antiviral action it does have a skin irritant 1 property but to neutralise that glycerine was used in 1:1000 emulsion

Conclusion: Acriflavine which was used in world warl as antiseptic solution for war wounds can be used for dressing of complicated ulcers and wounds to gainbetter results.

Keywords: Acriflavine, ulcer, dressing, wound.

\section{Introduction}

More and more cases of diabetic ulcers and complicated wounds are coming in routine Surgery opd. They are a relatively common occurrence for their dressing various method and materials are available such as EUSOL, povidone iodine, cadomeraseoxidase, natural honey ${ }^{[1,2]}$. One such solution is acriflavine which is made from acridine. It is having a skin Irritant property so to rectify that various method of preparing acriflavine have been developed. One such is acriflavine emulsion made using glycerine in 1:1000 amount.

\section{Corresponding Author:}

\section{Dr. Bhavin Shah}

Associate Professor, Smt. B.K. Shah Medical Institute and Research Centre, Sumandeep Vidyapeeth deemed to be university (An Institution), Pipariya Vadodara e-mail: narolaviraj@gmail.com

Phone :7874546371

\section{Case Presentation:}

Case 1: A 60 year old male patient presented to surgery opd with a large ulcer over left leg. A $10 * 10 \mathrm{~cm}$ ulcer was noted over left leg which was extending from knee joint to ankle joint . Patient was a known diabetic.

From 2 years and was on metformin $500 \mathrm{mg}$ bd. $\mathrm{He}$ gave a history of small abscess formation over anterior Aspect of knee joint which then turned into a large ulcer in 4 days. On examination the base was covered with thick pus with no healthy granulation tissue. The margins were not clearly defined .Edges were sloping.

On admission hb was $10.5 \mathrm{gm} / \mathrm{dl}$ tlc was 27000 per microlitre of blood. Urgent debridement was done. Which was followed by acriflavine emulsion dressing for 5 days and then STSG was performed. The graft was accepted and the post op course was uneventful. 

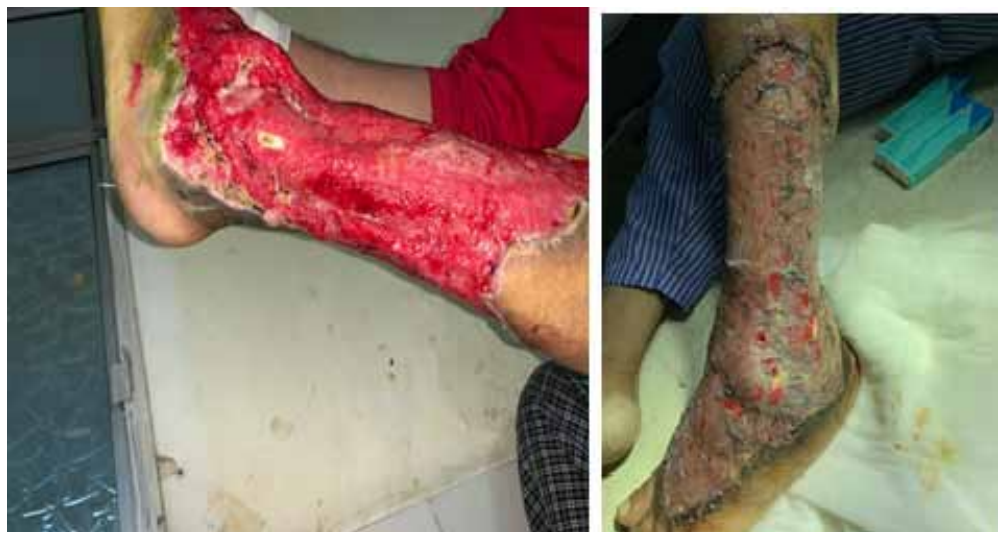

Figure 1: Showing Status of Wound on Admisiion (Right), After Grafting (Left)

Case 2: A 38 year old male working as a farmer came to casualty with a small ulcer over left thigh on examination the ulcer base was filled with pus and the whole leg from medial side of the ankle to lateral aspect of thigh filled with toxic material. $\mathrm{Hb}$ was 8.5 and total count was 45000 on doing serology patient was found to be hbsag positive. Urgently debridement was done following which EUSOL dressing was done for 5 days but no positive results were found then acriflavine emulsion was tried for 7 days following which STSG was done and $3 \mathrm{pcv}$ were transfused meanwhile to the Patient. The graft was fully accepted with uneventful post op course
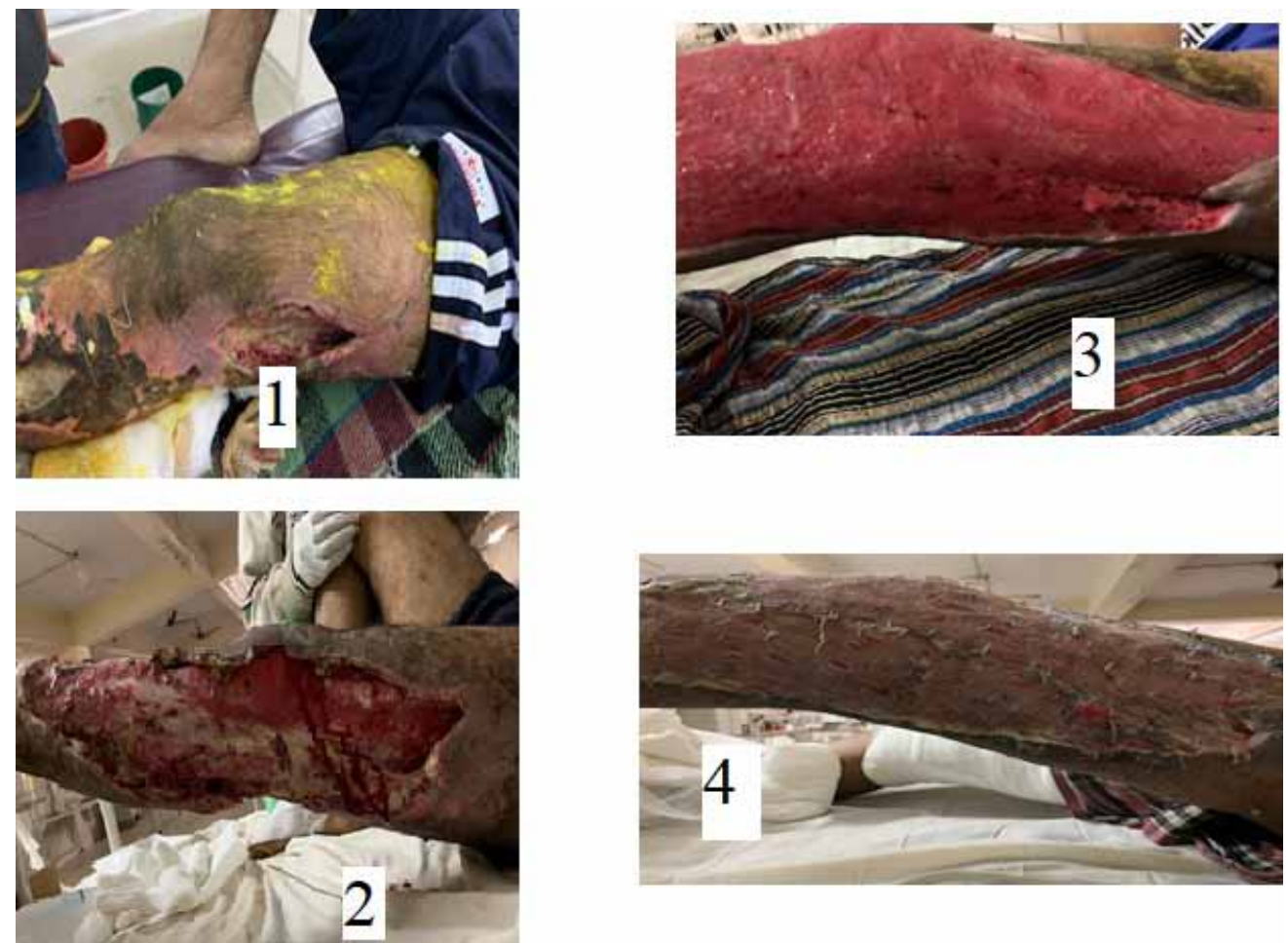

Figure 2: S/o 1. Patient condition on admission, 2. Results of EUSOL dressing, 3. Results of acriflavine deessing, 4. STSG graft well accepted.

\section{Discussion}

Acridine and its derivative posses specific antiseptic properties. ${ }^{3}$. Acriflavine being acridine derivative has broad spectrum coverage against bacterias. Unlike other antiseptics acriflavine can act even In highly infective conditions with minimal adverse effects Glycerine has 
soothing action over wounds and ulcers ${ }^{4}$.Glycerine Posses hygroscopic action. When acriflavine is used with glycerine (In 1:1000).glycerine provides hygroscopic action which helps acriflavine To penetrate more and directly in wounds and ulcers ${ }^{5}$ Generally, Pads and bandages soaked in this solution (1:1000, acriflavine: glycerine) Are directly applied over contaminated wounds and ulcers. Thus This solution provides antibacterial, antioxidant and hygroscopic Action over highly contaminated wounds and ulcers.

\section{Conclusion}

Acriflavine which was used in world war era for wound dressings can give positive results in complicated wounds

\section{Conflict of Interest: Nil}

Source of Funding: Self

Ethical Clearence: Taken from Sumandepp Vidyapeeth Institutional Ethics Committee.

\section{References}

1. Leelavathi M, Le Y, Tohid H, Hasliza A. Contact dermatitis presenting as non-healing wound: case report. Asia Pac Fam Med. 2011 May 15;10(1):6. doi: 10.1186/1447-056X-10-6. PMID: 21575147; PMCID: PMC3113738.

2. Stephen Thomas. The role of dressings in the treatment of moisture-related skin damage. Worldwidewounds2008 March.

3. Stowell TE. ACRIFLAVINE EMULSION AS A WOUND DRESSING. Br Med J. 1919 Mar 1;1(3035):244-5. doi: 10.1136/bmj.1.3035.244. PMID: 20769388; PMCID: PMC2340885.

4. Stout EI, McKessor A. Glycerin-Based Hydrogel for Infection Control. Adv Wound Care (New Rochelle). 2012 Feb;1(1):48-51. doi: 10.1089/ wound.2011.0288. PMID: 24527279; PMCID: PMC3839013.

5. Ousey K, Cutting KF, Rogers AA, Rippon MG. The importance of hydration in wound healing: reinvigorating the clinical perspective. J Wound Care. 2016 Mar;25(3):122, 124-30. doi: 10.12968/ jowc.2016.25.3.122. PMID: 26947692. 